Check for updates

Cite this: RSC Adv., 2019, 9, 21530

Received 15th April 2019

Accepted 26th June 2019

DOI: $10.1039 / c 9 r a 02848 j$

rsc.li/rsc-advances

\section{Effect of PVC film pretreatment on performance and lamination of wood-plastic composite plywood}

\author{
Zhihui Li, (D) a Xinglai Qi, ${ }^{a}$ Yanlong Gao, ${ }^{\text {a }}$ Yonghui Zhou, ${ }^{\mathrm{b}}$ Nairong Chen, ${ }^{\mathrm{a}}$ Qinzhi Zeng, ${ }^{\text {a }}$ \\ Mizi Fan (D)*ab and Jiuping Rao*ab
}

In order to solve the practical problem of heat transfer during the hot pressing process of a novel woodplastic composite plywood, this paper investigates the perforation treatment of polyvinyl chloride (PVC) plastic films and their plywood composites. The PVC films were pretreated by the physical punching method, and the effects of PVC perforation diameter, hot pressing time and hot pressing temperature on the mechanical properties of the plywood composites were investigated by orthogonal experimental design. The results showed that the optimum hot pressing time was $7 \mathrm{~min}$, the hot pressing temperature was $170{ }^{\circ} \mathrm{C}$, and the PVC perforation diameter was $15 \mathrm{~mm}$ for the optimum mechanical properties. The punching pretreatment of PVC films gave rise to a reduction of the hot pressing time by $51 \mathrm{~s}$ due to improved heat transfer and heat loss by $5.06 \%$, and allowed an increase in the initial moisture content of the veneer by $2-3 \%$, thereby cutting down the drying cost in the veneer production process, which is conducive to energy conservation and environmental protection.

\section{Introduction}

Wood based composites, such as plywood, particleboard, oriented strand board (OSB), medium density fiberboard (MDF), laminated veneer lumber (LVL) and Glulam, are commonly used for both structural and non-structural applications. ${ }^{1-3}$ These composites are usually produced using aldehyde adhesives, such as urea-formaldehyde resins (UF) and phenol-formaldehyde resins (PF), the production and products of which can release free formaldehyde. ${ }^{4-6}$ In particular, most of these composite panels are for indoor applications and release of harmful gases is very detrimental to people's health. In order to reduce the toxicity of wood-based composites, some researchers have attempted biomass-adhesives for the production, e.g. plant protein adhesives, blood glue, starch glue and bone glue..$^{7-9}$ However, these adhesives have high viscosity and are difficult to apply evenly, which may lead to unstable bonding of glue lines. In addition, biomass adhesives are prone to mildew and deterioration, and are not suitable for use in high humidity environments. Wood-plastic composite plywood have also recently been considered as one of alternative in some applications of wood based composites and the advantages of which are light weight, easy processing, good thermal insulation performance, rich texture and importantly no release of

${ }^{a}$ College of Materials Engineering, Fujian Agriculture and Forestry University, 350002, Fuzhou, Fujian, China. E-mail: fafurjp@163.com; fanfafu@gmail.com

${ }^{b}$ College of Engineering, Design and Physical Sciences, Brunel University London, Uxbridge UB8 $3 P H, U K$ formaldehyde, ${ }^{\mathbf{1 0}}$ and wood plastic composites have also the characteristics of water resistance, mildew resistance and chemical resistance.

Recently, there have been some attempts on the production of thermoplastic film/single laminate plywood by using polyvinyl chloride (PVC). As a thermoplastic films, the polyvinyl chloride (PVC) is waterproof, corrosion resistant, stable and sticky after hot melt. Compared with polyethylene (PE) ${ }^{\mathbf{1 1}}$ and polypropylene (PP), ${ }^{12}$ PVC has the characteristics of low price and wider source. Compared with commonly used adhesives, such as UF and PF, it does not contain harmful substances such as formaldehyde. ${ }^{13}$

However, as a non-polar or slightly polar substance, plastic was difficult to combine with hydrophilic wooden material (fiber, particle or veneer) as polar substance does. ${ }^{\mathbf{1 4 - 1 6}}$ Therefore, researchers try various methods to treat wooden materials or thermoplastic, mainly including physical treatment and chemical treatment. ${ }^{17-19}$ For example, Matuana, et $a .^{20}$ and Song, et $a .^{21}$ treated wood veneers with various coupling agents to improve the compatibility between PVC and wood fibers. Murata, et al. ${ }^{22}$ and Temiz, et al. ${ }^{23}$ reported that the mechanical properties of plywood were increased by heat and steam treatment of veneers. Wei, et al. $^{24}$ analyzed the effects of 3-aminopropyl(triethoxy) silane modification on various properties of veneers and composites and Lin, et al. ${ }^{25}$ punched holes in the wood veneer, with plastic films alternative adhesive in plywood production, films heating to melt and penetrate into pinholes to improve bonding performance. Nevertheless, these methods have not solved the problem of slow heat transfer during hot 
press forming of plywood or other laminates, as the presence of a non-porous thermoplastic plastic films hinders the transfer of heat and prolongs the hot pressing time. ${ }^{26}$ This will lead to a decrease in production efficiency, an increase in energy consumption and a further increase in production cost, because the completion of the bonding between the veneer and the PVC plastic films was closely related to the heat transferred through the water vapor to the core layer under a certain pressure.

To improve the heat transfer during the hot pressing process and hence comprehensive performance of composite plywood laminates, this research is to use the physical method to uniformly perforate the PVC films, enabling to promote the heat transfer and achieve a full melting of PVC films of the core layer in a short time. This is not only able to speed up the heat transfer process and improve bonding between PVC films and wood veneer, but also to appropriately increase the initial moisture content of the veneer, which is beneficial for energy saving. The study develops PVC-Eucalyptus veneer composite plywood laminates through hot pressing process, and investigates the effect of PVC perforation diameter, pressing time and hot pressing temperature on the mechanical properties and thermal stability of the laminates. The orthogonal test design is employed to reduce the number of the experiments, and the interface bonding status of plywood composite laminates is characterized by a field emission scanning electron microscope to analyze its morphology before and after the treatment of the PVC films. It was further verified that the PVC films perforate is beneficial to accelerate the heat transfer rate and improve the mechanical properties of the wood-plastic composite plywood by using various initial moisture contents of veneers.

\section{Materials and methods}

\subsection{Materials}

The Eucalyptus veneers were supplied by Nanping Yuanqiao Wood Industry Co. (China). The size of the veneers was $300 \mathrm{~mm}$ $\times 300 \mathrm{~mm} \times 2.3 \mathrm{~mm}$ and its moisture content was $10-11 \%$. The PVC films were supplied by Changzhou Yuandong Advanced Plastic Co. (Jiangsu, China). The specification of PVC films was $300 \mathrm{~mm} \times 300 \mathrm{~mm} \times 0.1 \mathrm{~mm}$ and its density was $1.45 \mathrm{~g} \mathrm{~cm}^{-3}$. The PVC films were punched evenly, as shown in Fig. 1 . The

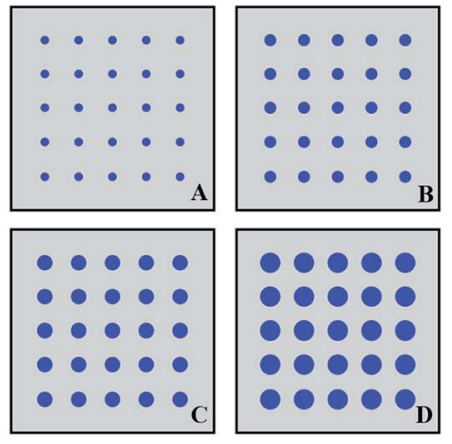

Fig. 1 PVC films pretreated with different pore sizes (A, B, C and D opening diameters were $5 \mathrm{~mm}, 10 \mathrm{~mm}, 15 \mathrm{~mm}$ and $20 \mathrm{~mm}$ respectively). diameters of the punched holes are $5 \mathrm{~mm}, 10 \mathrm{~mm}, 15 \mathrm{~mm}$ and $20 \mathrm{~mm}$.

Silane coupling agent KH550 with the active ingredient content of $97 \%$ was purchased from Chenguang Coupling Co. (Jiangsu, China). The loading of the silane coupling agent was $1 \%$ of PVC films.

\subsection{Design of orthogonal scheme}

To efficiently develop the PVC-wood plywood composites and reduce the number of experiments, the statistic orthogonal design was employed, the parameters of which were also decided by taking into consideration of the hot melt temperature of PVC films (Fig. 3). This experimental design allows a comprehensive investigation on the effect of pretreatment of PVC films on heat transfer of composite plywood along with pressing parameters, that is, according to the design principle of orthogonal test $\mathrm{L}_{16}\left(4^{5}\right),{ }^{27}$ the effects of different hot pressing temperature, hot pressing time and different pore size PVC films on the physical and mechanical properties of the developed plastic-wood plywood composites can be interpreted. The process parameters of the screening are given in Table 1.

\subsection{Plywood composites preparation}

The coupling agent, KH550, was diluted with absolute ethanol, and sprayed evenly on both sides of the PVC films. After the ethanol volatilized, the designed and pretreated PVC films were laminated with veneers as shown in Fig. 2. It must be noted that the assembling procedure follows those used in the plywood production, the principle of which is that the veneers are crosslaminated between the adjacent layers, i.e. the grain of the surface ply is in line with the longitudinal direction of the plywood composites, followed by the next ply with its grain direction $90^{\circ}$ (perpendicular) to the longitudinal direction of the plywood composites. PVC plastic films mainly works as the glueline connecting between two veneers. Each composite mat consists of five plys of veneer and four layers of PVC. After assembly, the composite mat was placed in a hot-pressing machine (KSH-100T; Dongguan Kesheng Industrial Co.), and both heat and pressure were applied to obtain plywood composites with the final thickness of $10 \mathrm{~mm}$. The hot pressing pressure was $2 \mathrm{MPa}$ and various combinations of hot pressing time and temperature were designed as shown in Table 2. The above procedure was repeated to prepare PVC plywood

Table 1 Experimental factors and levels

\begin{tabular}{llll}
\hline & Factors & \\
\cline { 2 - 4 } Levels & $\begin{array}{l}\text { Hot pressing } \\
\text { time }(\mathrm{A}) / \mathrm{min}\end{array}$ & $\begin{array}{l}\text { Hot pressing } \\
\text { temperature }(\mathrm{B}) /{ }^{\circ} \mathrm{C}\end{array}$ & $\begin{array}{l}\text { Hole size of } \\
\text { PVC }(\mathrm{C}) / \mathrm{mm}\end{array}$ \\
\hline 1 & 6 & 150 & 5 \\
2 & 7 & 160 & 10 \\
3 & 8 & 170 & 15 \\
4 & 9 & 180 & 20
\end{tabular}




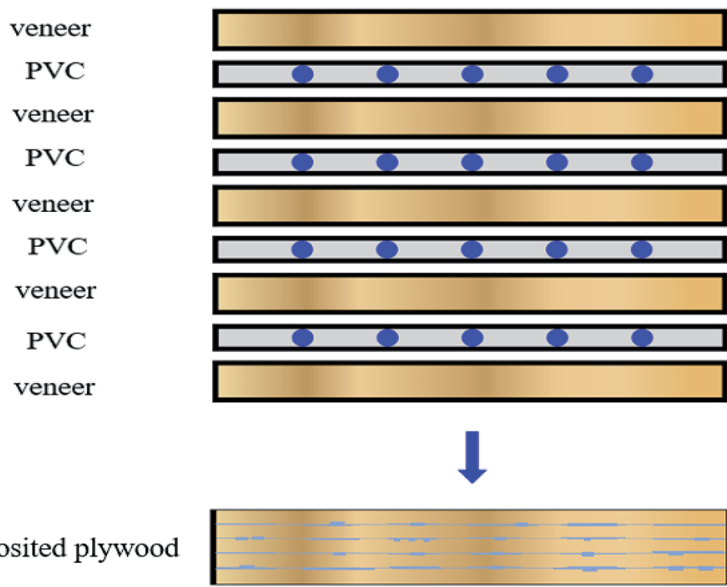

Fig. 2 Combination structure of plastic plywood composites.

composites having four different perforation geometric diameters of $5 \mathrm{~mm}, 10 \mathrm{~mm}, 15 \mathrm{~mm}$ and $20 \mathrm{~mm}$.

\subsection{Characterization}

2.4.1 Determination of the optimum hot pressing temperature. To effectively develop the glueline for the composites, the melting temperature is the key for production, that is, the process needs to ensure that the temperature is high enough to generate complete flow of PVC during the hot pressing. On the other hand, the temperature should not be too high, which may result in a degradation of the wood veneer and also the decomposition of the plastic. The melting temperature of the PVC films was measured by differential scanning calorimetry (DSC8500; PerkinElmer Enterprise Management Co. America). The test was carried out under a nitrogen atmosphere as a shielding gas, with an initial temperature of $30{ }^{\circ} \mathrm{C}$, a termination temperature of $200{ }^{\circ} \mathrm{C}$ and a heating rate of $5{ }^{\circ} \mathrm{C} \min ^{-1}$.
2.4.2 Determination of the hot pressing time. In order to observe the change of the core layer temperature during the hot pressing of the plywood composite and the time required for the core layer temperature to reach the target temperature, the test deliberately extended the hot pressing time to $1000 \mathrm{~s}$. The experiment used a digital thermometer (TM-902C/DM6902; Shenzhen Vichy Electronic Technology Co. China), the temperature probe of the thermometer was buried in the core layer of the composite plywood without perforation, and the other end was connected to the logger and data display, which recorded the temperature $\left({ }^{\circ} \mathrm{C} \mathrm{s}^{-1}\right)$, observed the time required for the temperature of the core layer to rise to $170{ }^{\circ} \mathrm{C}$ and then generated the heat transfer curve of the wood-plastic composite plywood with un-perforated PVC films.

2.4.3 Mechanical properties. The pressed plywood composites were conditioned at room temperature for two days before mechanical testing. 12 test pieces were sampled according to the two directions of the panel in the longitudinal and transverse directions with the dimension $250 \mathrm{~mm} \times 50 \mathrm{~mm}$ $\times 10 \mathrm{~mm}$ for the modulus of rupture (MOR) and modulus of elasticity (MOE) tests in accordance with the standard ISO 16978 (2003). 12 test pieces for bonding strength were sampled with the dimension $100 \mathrm{~mm} \times 25 \mathrm{~mm} \times 10 \mathrm{~mm}$ in accordance with the standard ISO 12466-1 (2007). Tests were carried out with a universal test machine (E44.304: Meters Industrial Systems (China) Co., Shenzhen, China) and the average of the 12 tests was taken for each group.

2.4.4 Thermal stability. The PVC-wood composite plywood laminate was grinded to prepare test pieces. The thermal stability of the plywood laminates with various pore sizes were evaluated by a thermal conductivity analyzer (Netzsch STA449F3 Jupiter; NETZSCH-Gerätebau GmbH, Selb, Germany), the temperature range of which was set to $25-350{ }^{\circ} \mathrm{C}$, the test media was nitrogen and the heating rate was $10{ }^{\circ} \mathrm{C} \mathrm{min}^{-1}$. After a blank test was performed to obtain baseline data, the sample was weighed $4.00 \pm 0.05 \mathrm{mg}$ into the alumina crucible and then

Table 2 Mechanical properties and processing parameters of wood-plastic composite plywood

\begin{tabular}{|c|c|c|c|c|c|c|}
\hline Trial & Pressing time (A) & Pressing temperature (B) & Hole size of PVC (C) & Bonding strength (MPa) & MOR (MPa) & MOE (MPa) \\
\hline 2 & 2 & 2 & 2 & 0.65 & 41.0 & 3931 \\
\hline 3 & 3 & 3 & 3 & 0.73 & 46.3 & 4510 \\
\hline 4 & 4 & 4 & 4 & 0.61 & 37.1 & 3820 \\
\hline 7 & 3 & 4 & 1 & 0.49 & 31.1 & 3010 \\
\hline 8 & 4 & 3 & 2 & 0.68 & 39.8 & 3902 \\
\hline 9 & 1 & 3 & 4 & 0.74 & 46.2 & 4552 \\
\hline 10 & 2 & 4 & 3 & 0.76 & 47.0 & 4604 \\
\hline 11 & 3 & 1 & 2 & 0.53 & 33.9 & 3495 \\
\hline 12 & 4 & 2 & 1 & 0.46 & 30.1 & 2979 \\
\hline
\end{tabular}


the sample containing the crucible was positioned on a position with the STA sensor. By repeating the above procedure, the thermal stability of PVC-wood composite plywood laminates with different pore sizes was analyzed.

2.4.5 Morphological observation. The interface bonding status of plywood composite laminates between the veneers and PVC films before and after the treatment of the PVC films were investigated using a field emission scanning electron microscope (Nova Nano SEM 230; FEI Company, Tokyo, Japan). Samples of about $0.5 \mathrm{~cm} \times 0.5 \mathrm{~cm}$ were taken at the glueline of adjacent layer of PVC-wood composite plywood laminates and pasted on the carrier plate. The samples were then sprayed with gold and finally put into the electron microscope. The distribution of PVC films in the veneer and their combination were observed by Nova Nano SEM230.

2.4.6 Relationship between water content and mechanical properties. Based on the parameters optimized by orthogonal experiment, the mechanical properties of PVC-wood plywood laminates with PVC films before and after punching were further investigated by using various initial moisture contents of veneers, namely $7 \%, 8 \%, 9 \%, 10 \%, 11 \%$ and $12 \%$ moisture content of veneers.

\section{Results and discussion}

\subsection{Hot melt temperature of PVC plastic films}

Thermal characteristic of PVC is one of the most important parameters for the production of the PVC-wood plywood composites. It decides the hot pressing parameters and the glueline quality of the composites. It can be seen that the hot melt temperature of the PVC films was $135{ }^{\circ} \mathrm{C}$ (Fig. 3), which indicates that the PVC films can be melted and adhesively applied only when the temperature was higher than $135^{\circ} \mathrm{C}$. This means that the hot pressing temperature for the composite production should be at least equal to or higher than $135{ }^{\circ} \mathrm{C}$. The decomposition temperature of the PVC films used in this experiment was as high as $280{ }^{\circ} \mathrm{C}$, so the actual hot pressing temperature was reasonable to take $135-280{ }^{\circ} \mathrm{C}$. It must be

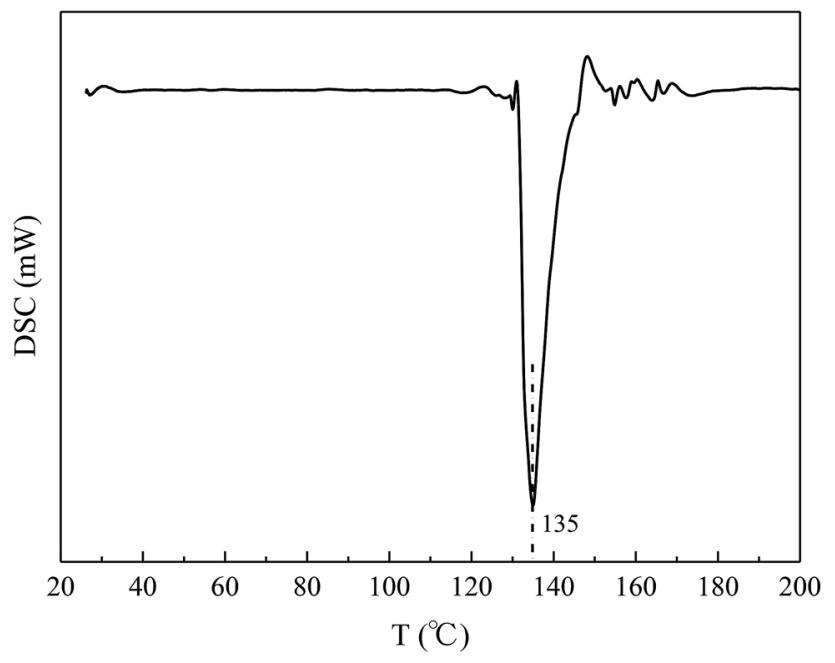

Fig. 3 DSC diagram of PVC films. noted that determining a specific temperature is related to the thickness of composites, property of veneers and the duration of pressing time, as they will affect the heat transferring through the thickness of the composites. In general, the hot pressing temperature is appropriately increased to allow a full melting of the PVC films, especially films/glueline in the centre of the composites. Nevertheless, this may also be achieved by increasing the duration of time. Too high temperature or lengthy exposure of both films and veneer may result in the decomposition of the materials. Therefore, it is vital to design an appropriate hot pressing process to ensure the full melting and distribution of PVC across the glueline and penetration into veneer, but the same time avoid the deterioration of composites, and this can only be achieved with a good understanding of temperature profile, which is hence discussed in the next section.

\subsection{Temperature profile of the core layer of PVC-wood plywood composites}

The heat transfer and distribution of temperature are closely related to the temperature of hot plate and thickness of the composite. Fig. 4 shows the PVC composite plywood laminates without perforation, the core layer temperature of plywood composites changed with the hot pressing time, when the hot pressing temperature (press plate temperature) was $170{ }^{\circ} \mathrm{C}$. It can be seen that the heat transfer in the plywood composites core follows a polynomial change and the heat transfer process can be divided into four stages. The first stages from the beginning to $100 \mathrm{~s}$, the temperature rose rapidly, as the difference between the hot press and the composite mat was large, as soon as the plate was in contact with the mat, resulting in a rapid transfer of heat from the hot plate to the low temperature composite mat and hence a rapid increase in the core layer temperature from $20^{\circ} \mathrm{C}$ to $110^{\circ} \mathrm{C}$. The second stages in the next $200 \mathrm{~s}$, heat transfer did not result in a significant rise in core temperature, even constant at $110{ }^{\circ} \mathrm{C}$ from $100 \mathrm{~s}$ to $150 \mathrm{~s}$. A number of reasons may contribute to this slowdown of the heat transfer rate and temperature rise at this stage: (1) the

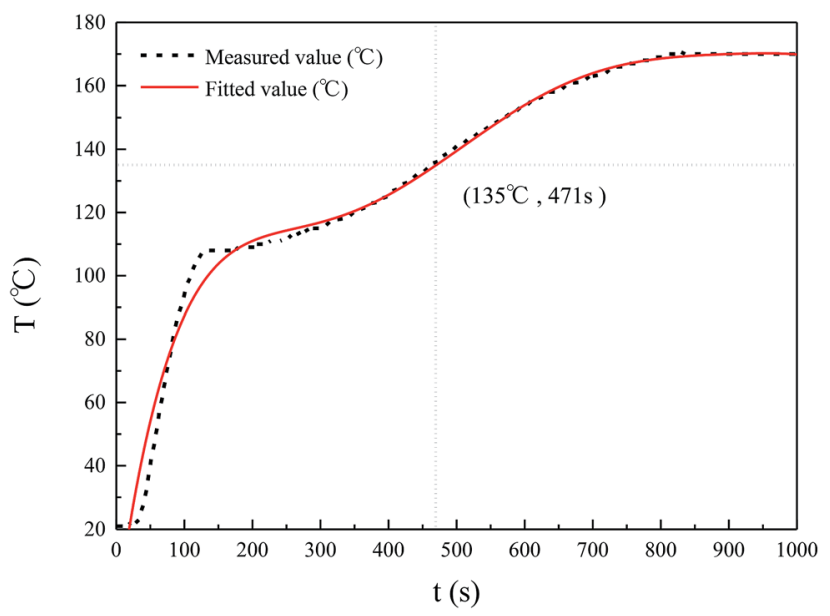

Fig. 4 Heat transfer curve of the core layer in wood-plastic composite plywood. 
temperature difference between the hot plate and the composites mat was reduced; (2) the moisture in the surface layers of the composite mat may start to move to the surface and evaporate, which absorb heat/energy and (3) the heat transfer could be hindered by the presence of the PVC films which requires heat for its melting. The third stage from $300 \mathrm{~s}$ to $830 \mathrm{~s}$, the core temperature rises faster again, because the PVC films gradually softened and melted, and the resistance to heat transfer was gradually reduced. Therefore, the temperature rises faster in this stage than in the second stage. The last stage from about $830 \mathrm{~s}$, the temperature difference between the press temperature and the plywood composite mat gradually decreases, the heat transfer rate was slowed down and the core temperature approached stable.

The temperature change in the composite core can also be fitted statistically with polynomial equation, giving a high degree of mathematic $R^{2}=0.98835$, as follows:

$$
\begin{gathered}
Y=1.594 X-8.45 \times 10^{-3} X^{2}+2.244 \times 10^{-5} X^{3}-3.014 \times 10^{-8} X^{4} \\
+1.985 \times 10^{-11} X^{5}-5.128 \times 10^{-15} X^{6}-7.163
\end{gathered}
$$

The plot of core temperature profile also allows an identification of minimum pressing time for the production of PVCwood plywood composite, but ensure melting of PVC and bonding of veneers. It is apparent that when setting the hot pressing temperature to $170{ }^{\circ} \mathrm{C}$, the minimum hot pressing time should be $471 \mathrm{~s}$ to ensure that the core layer reaches $135{ }^{\circ} \mathrm{C}$ and the PVC films can be completely melted, flow and penetrate into veneers, and hence achievement of quality bonding strength.

\subsection{Mechanical properties of PVC-wood laminates}

According to the test parameters and levels given in Table 1, 16 sets of test protocols were designed to understand the effect of processing parameters on the bonding strength, modulus of rupture (MOR) and modulus of elasticity (MOE) (Table 2). Each data was the average of 3 test results.

MOR, MOE and bonding strength in relation with individual processing parameters and their levels are computed and given in Table 3. The results of the range analysis of the bonding strength showed that the pressing time, temperature and PVC pore size all had a certain influence on the bonding strength of the plywood laminates. Among them, the largest $R$ value was the PVC pore size, indicating that the uniform opening treatment of PVC had the greatest influence on the bonding strength of the plywood laminates, followed by the temperature of the pressing. The minimum $R$ value was the pressing time. It can be concluded that the optimum level combination was $7 \mathrm{~min}$ of pressing time, $170{ }^{\circ} \mathrm{C}$ of pressing temperature and $15 \mathrm{~mm}$ of PVC pore size.

The results of the range analysis of both MOR and MOE showed that the largest $R$ value was again the PVC pore size, indicating that the PVC opening treatment has the greatest influence on the MOR of the plywood laminates, followed by the pressing time for MOR, but the pressing temperature for MOE. The optimum level combination of the optimum MOR and MOE was $7 \mathrm{~min}$ of pressing time, $170{ }^{\circ} \mathrm{C}$ of pressing temperature and $15 \mathrm{~mm}$ of PVC pore size, which are the same as those for the optimum bonding strength.

A scrutiny of the results showed that as the pressing time increases, the bonding strength first increases and then decreases. When the pressing time was $7 \mathrm{~min}$, the bonding strength reached $0.68 \mathrm{MPa}$. The pressing time less than $7 \mathrm{~min}$ means that the core layer temperature may not reach the melting temperature of PVC plastic (Fig. 4), which leads to the incomplete melting of PVC and hence poor bonding strength. A slight lower temperature of $7 \mathrm{~min}(420 \mathrm{~s})$ in comparison to the aforementioned $471 \mathrm{~s}$ was that the former is with PVC

\begin{tabular}{|c|c|c|c|c|}
\hline \multirow[t]{3}{*}{ Bonding strength (MPa) } & $\overline{\mathrm{K} 1}$ & 0.610 & 0.535 & 0.465 \\
\hline & $\overline{\mathrm{K} 3}$ & 0.590 & 0.688 & 0.695 \\
\hline & $\overline{\mathrm{K} 4}$ & 0.585 & 0.637 & 0.667 \\
\hline \multirow[t]{6}{*}{ MOR (MPa) } & $\overline{\mathrm{K} 1}$ & 38.950 & 35.900 & 31.750 \\
\hline & $\overline{\mathrm{K} 2}$ & 42.900 & 37.825 & 38.625 \\
\hline & $\overline{\mathrm{K} 3}$ & 37.300 & 42.650 & 43.125 \\
\hline & $\overline{\mathrm{K} 4}$ & 35.975 & 38.750 & 41.625 \\
\hline & $R$ & 6.925 & 6.750 & 11.375 \\
\hline & Superior level & $\mathrm{A}_{2}$ & $\mathrm{~B}_{3}$ & $\mathrm{C}_{3}$ \\
\hline & $R$ & 584.750 & 673.000 & 1322.750 \\
\hline & Superior level & $\mathrm{A}_{2}$ & $\mathrm{~B}_{3}$ & $\mathrm{C}_{3}$ \\
\hline
\end{tabular}

Table 3 Range analysis of the main performance 
perforated while the latter with PVC without perforated hole, namely there was time difference to $51 \mathrm{~s}$ between them. Increase in the pressing time, e.g. $8 \mathrm{~min}$ and $9 \mathrm{~min}$, may result in an increase in the flow of the melt PVC and penetration into the crack of the veneer, which had a negative effect on the bonding strength. The bonding strength was the best when the pressing temperature was $170{ }^{\circ} \mathrm{C}$, because low temperature affected the heat transfer efficiency and too high temperature caused premature melting of PVC films, resulting in poor bonding strength between the veneers. It can also be seen that the pore size played an important role on the bonding strength. Small holes may not give sufficient path for the heat transfer, while increase in the size of the hole is equivalent to the reduction of the added PVC. The bonding strength was the best when the hole diameter was $15 \mathrm{~mm}$. The similar trend is found for the change of the MOR and MOE in relation to the pressing time, pressing temperature and PVC pore size. All processing parameters result in an increase and then decrease of MOR and MOE, which can be explained with the similar principle as those of the bonding strength. It can be clearly seen that the optimal process parameters were pressing temperature of $170{ }^{\circ} \mathrm{C}$, pressing time of $7 \mathrm{~min}$, and PVC pore size of $15 \mathrm{~mm}$.

The variance analysis of MOR, MOE and IB is given in Table 4. It can be seen that for the bonding strength, the F value of the PVC pore size was 15.176 , which was greater than $F_{0.01}(3,6)$. This means that the influence of the PVC pore size on the bonding strength was extremely significant, indicating that the hole punching treatment of the PVC films can significantly benefit the heat transfer during the pressing process. The $\mathrm{F}$ value of temperature was 5.765 , which was between $F_{0.05}$ and $F_{0.01}$, therefore, the influence of pressing temperature was significant. The role of the pressing temperature was to ensure the melting of the PVC films in a certain temperature, which is essential for generating glueline and bonding veneer. The pressing temperature creates the necessary conditions for enhancing the bonding strength. The $\mathrm{F}$ value of pressing time was 2.706 , which was less than $F_{0.1}$, indicating the effect of pressing time on the bonding strength was not significant.
From the analysis of variance of MOR, it can be seen that the $F$ value of the pressing time was 9.344 and the $F$ value of the temperature was 8.351. Both located between $F_{0.05}$ and $F_{0.01}$, therefore, the pressing time and pressing temperature had a significant effect on MOR. The $F$ value of PVC pore size was 26.386, which was greater than $F_{0.01}(3,6)$, and such the effect of PVC perforation size on MOR was extremely significant. The perforation treatment of the PVC plastic films facilitates the heat transfer and the PVC films between the veneers cured completely, thereby improving the MOR.

It can be seen from the variance analysis of the MOE of the PVC-wood laminates that $F$ values of the time and temperature was 3.415 and 3.892 respectively, which were located between $F_{0.1}$ and $F_{0.05}$. Therefore, so the influence of pressing time and pressing temperature on MOR were generally significant. The $F$ value of the PVC pore size was 17.603 , which was greater than $F_{0.01}(3,6)$, so the effect of PVC pore size on MOR was extremely significant.

Overall, it is evident that the effect of PVC perforation pretreatment on the mechanical properties of PVC-wood laminates was extremely significant. Compared with the PVCwood laminates with PVC no perforated holes, the hot pressing time was shortened by $51 \mathrm{~s}$, which greatly improved the production efficiency.

\subsection{Interface between PVC and veneer}

The microstructures of PVC-wood laminate with PVC films perforated treatment were given in Fig. 5A and $\mathrm{B}$. It can apparent that the veneer was well connected by organic PVC films and formed a good mechanical nail force and combined firmly with the veneers. The magnification of the interface indicates that the PVC melted completely (Fig. 5B) and gave a good ductility, thereby improving the bonding strength of the composite laminates. Fig. 5C and D are microstructures images of the distribution of PVC films without perforated pretreatment. It can be seen that the PVC films did not melt completely and generated poor adhesion, which was disadvantageous for enhancing the bonding strength between the veneers. ${ }^{\mathbf{2 8 , 2 9}}$ The

Table 4 Variance analysis of the main performance ${ }^{a}$

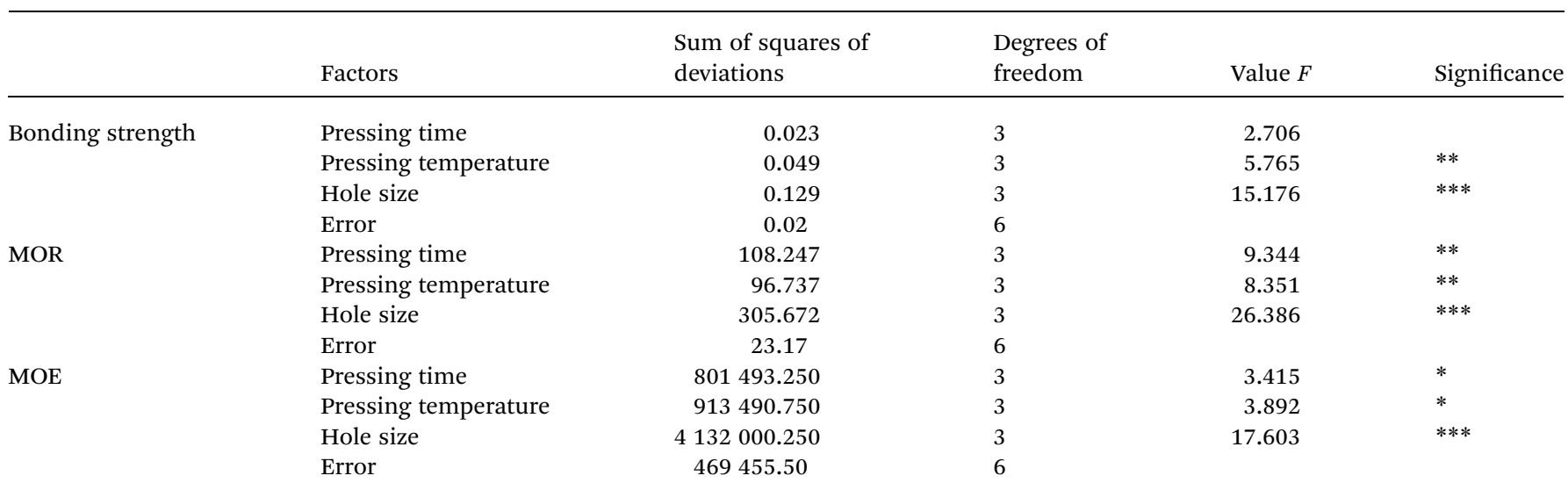

${ }^{a} F_{0.1}(3,6)=3.290, F_{0.05}(3,6)=4.760, F_{0.01}(3,6)=9.780$. When $F<F_{0.1}$, the influence of factors on performance indicators was not significant; when $F_{0.1}<F<F_{0.05}$, the influence of factors on performance indicators was generally significant, expressed by “*”; when $F_{0.05}<F<F_{0.01}$, the influence of factors on performance indicators was more significant, expressed by “**”; when $F>F_{0.01}$, the influence of factors on performance indicators was extremely significant, expressed by “****”. 
untreated PVC films may affect the heat transfer and evaporation of water vapor of the composite laminates during hot pressing. In a limited hot pressing time and temperature, the PVC films could not be completely melted and/or flow, therefore, the bonding between the veneers was poor. By contrast, the perforated PVC films may facilitate the heat transfer and the evaporation of water vapor, leading to a more completed melting of the PVC films and building up of bonding force and improvement of bonding strength.

\subsection{Thermal stability of PVC-wood laminates}

Thermogravimetric (TG) curves of composite laminates with different pretreatments under nitrogen atmosphere are shown in Fig. 6. It can be seen that the thermal degradation process for the four laminates appears to be divided into two major mass loss stages from $25{ }^{\circ} \mathrm{C}$ to $350{ }^{\circ} \mathrm{C}$ (Table 5): The first stage was at $25-100{ }^{\circ} \mathrm{C}$, the mass loss was about $5 \%$, which may result from the removal of a small amount of free water in the veneer. The major degradation occurred in the second stage between $100{ }^{\circ} \mathrm{C}$ and $350{ }^{\circ} \mathrm{C}$, which mainly corresponds to hemicellulose and cellulose decomposing in to char residues, and $\mathrm{CO}_{2}, \mathrm{CO}, \mathrm{CH}_{4}$, $\mathrm{CH}_{3} \mathrm{OH}$ and $\mathrm{CH}_{3} \mathrm{COOH},{ }^{30}$ and to the decomposition reaction of PVC films.

The perforated hole seems to have an influence on the degradation of PVC-wood laminates. Increasing the diameter of holes resulted in a delay of mass loss (Fig. 6). This again may be due to that small hole may hinder the heat transfer, resulting in local over heat and hence increase in mass loss. The mass

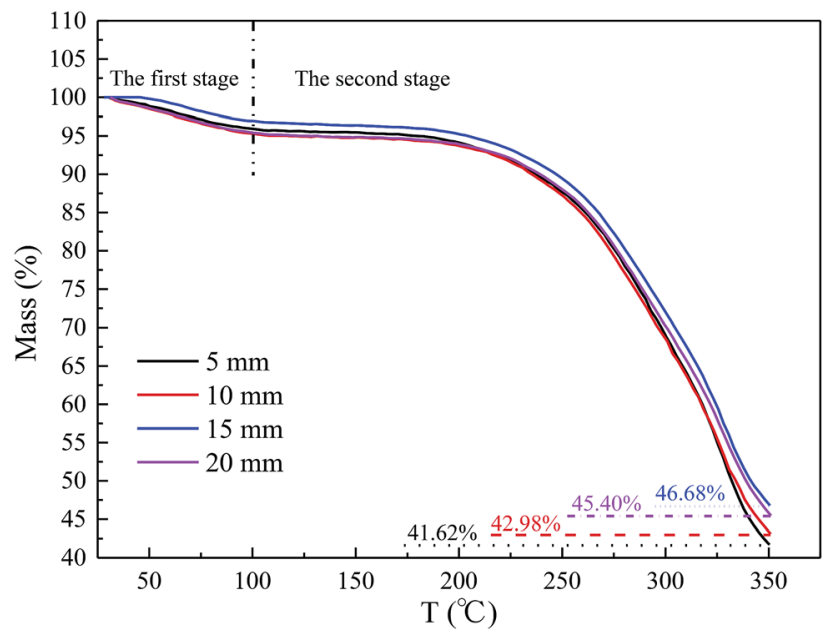

Fig. 6 Mass loss of PVC-wood laminate with different perforated diameters.

retention at $350{ }^{\circ} \mathrm{C}$ was about $41.62 \%$ for the $5 \mathrm{~mm}$ hole composite laminate and $46.68 \%$ for the $15 \mathrm{~mm}$ hole composite laminates. The latter was about $5.06 \%$ higher that former. It can be concluded that an appropriate pre-treatment of PVC films can effectively accelerate the heat transfer rate, generate the PVC films adhesion to the veneer, and form a compact and dense bonding region, meanwhile it may also avoid a local overheating and reduce mass loss, thereby improving thermal stability of composite plywood laminates. However, the veneer cannot be completely wrapped by the PVC films if the perforated
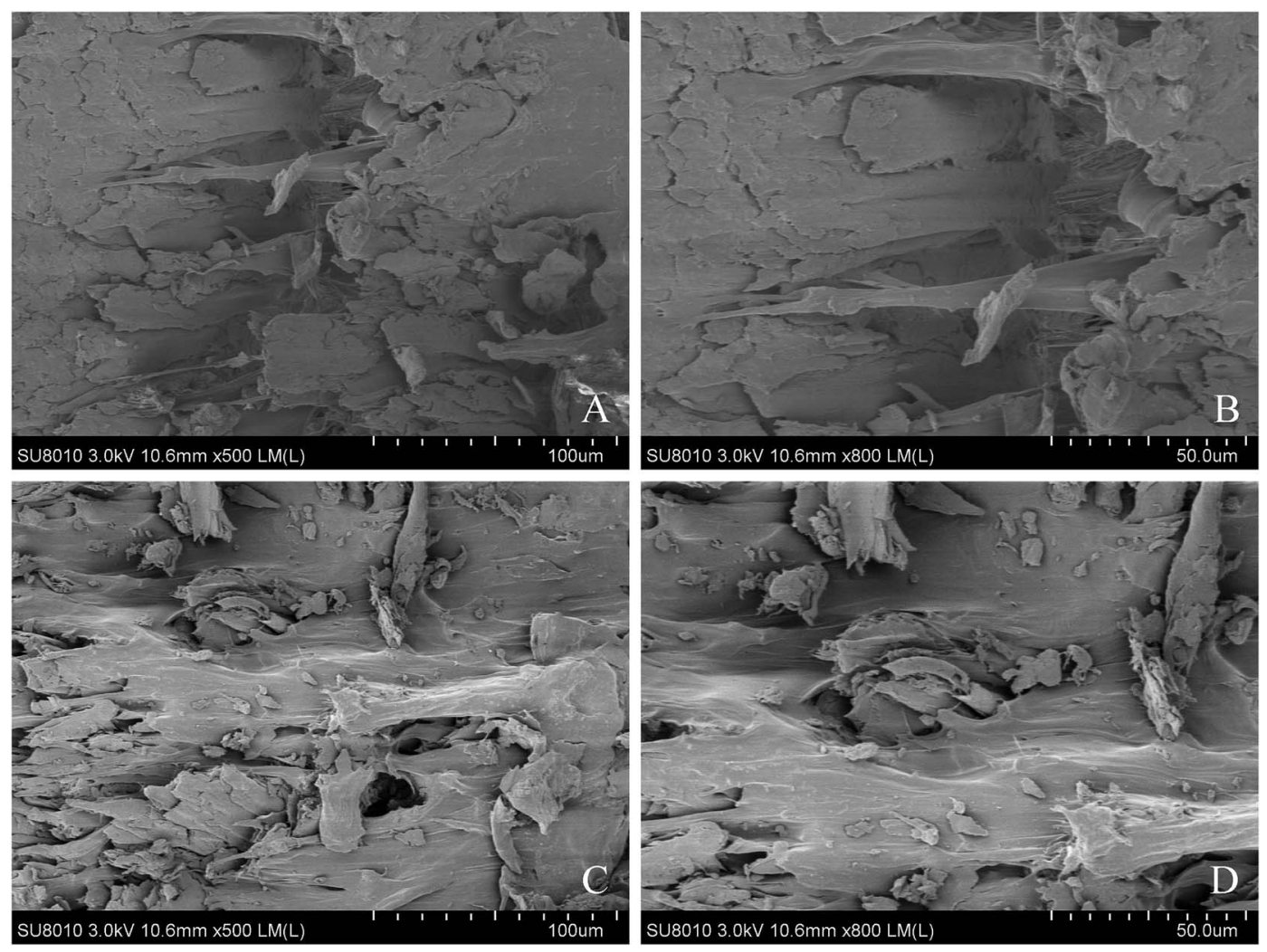

Fig. 5 Microstructures of veneer combined with PVC films with and without perforated holes. 
Table 5 Degradation of four types of composite laminates in two stages

\begin{tabular}{lll}
\hline Types & $\begin{array}{l}\text { Loss of the first } \\
\text { stage (\%) }\end{array}$ & $\begin{array}{l}\text { Loss of the second } \\
\text { stage }(\%)\end{array}$ \\
\hline $5 \mathrm{~mm}$ & 4.18 & 54.2 \\
$10 \mathrm{~mm}$ & 5.07 & 51.95 \\
$15 \mathrm{~mm}$ & 3.03 & 50.29 \\
$20 \mathrm{~mm}$ & 5.08 & 49.52
\end{tabular}

diameters is too large, thereby lowering the thermal stability of the wood-plastic composite plywood.

\subsection{Effect of moisture content of veneer on mechanical properties of plywood laminates}

Moisture content of veneer affects not only the bonding of wood veneer and PVC, but also heat transfer during the hot press. To further understand the effect of moisture on the property of the laminates, various initial moisture contents of veneer, ranging from $7 \%$ to $12 \%$ were studied. The optimal hot pressing process conditions, namely hot pressing pressure $2 \mathrm{MPa}$, hot pressing time $7 \mathrm{~min}$ and hot pressing temperature $170{ }^{\circ} \mathrm{C}$, and the PVC films with the best punching diameter of $15 \mathrm{~mm}$ were employed to produce composite plywood laminates.

It can be seen in the Fig. 7 that the mechanical properties of the PVC-wood laminates gradually increased and then decreased with the moisture content of the veneers increased from $7 \%$ to $12 \%$, indicating that the initial moisture content of the veneer had a significant effect on the performance of the plywood laminates. When the moisture content of the veneers was the same, the composite plywood laminates produced with the perforated PVC films again gave rise to a higher mechanical properties compared to those with the un-perforated PVC films. The increase of veneer moisture content from $7 \%$ to $10 \%$ resulted in an increase for unperforated PVC-wood laminates in MOR from 39.5 MPa to 42.9 MPa, MOE from $3000 \mathrm{MPa}$ to $3900 \mathrm{MPa}$ and bonding strength from $0.45 \mathrm{MPa}$ to $0.73 \mathrm{MPa}$. This may be due to that an increase in moisture content facilitate the heat transfer and hence the melting of PVC and its flow across the glueline and thickness of veneers. Further increase in moisture content of veneer did not give further an increase in
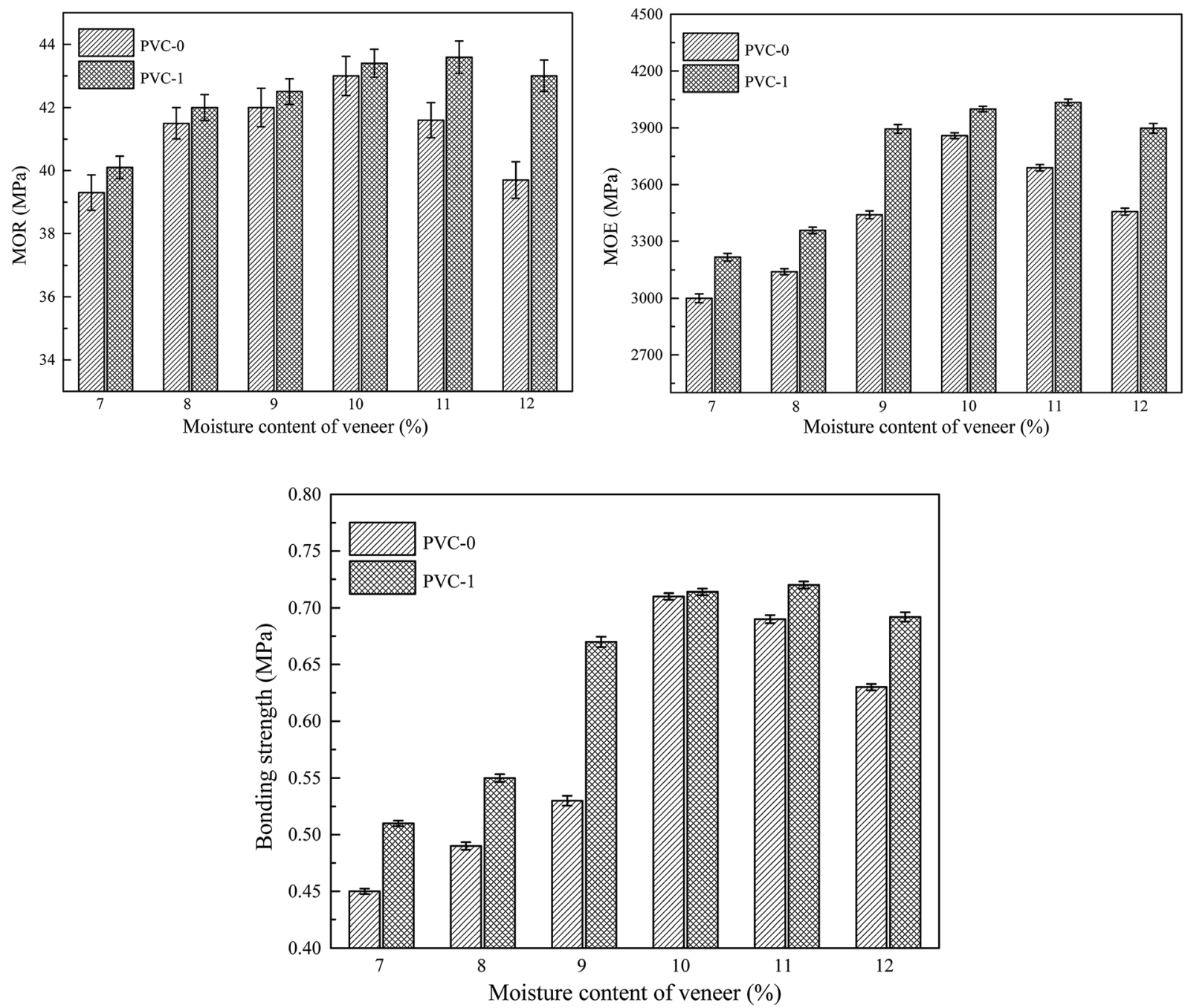

Fig. 7 Effect of moisture content of veneer on mechanical properties (PVC-0: un-perforated PVC films plywood laminates; PVC-1: perforated PVC films plywood laminate with a hole diameter of $15 \mathrm{~mm}$ ). 
the mechanical properties, rather a slight decrease. This is because too much moisture may produce too much water vapour in glueline, hindering the contact and bonding with hydrophobic PVC. The mechanical properties of the composite plywood laminates produced with the perforated PVC films reached a maximum at a moisture content of $11 \%$ while the mechanical properties of composited plywood produced from un-perforated PVC films reached a maximum at 10\% moisture content of the veneers. This means that a physical punching of PVC films is beneficial to accelerate the heat transfer rate. Therefore, it is allowed to use a higher initial moisture content of veneers for the production of plywood laminates, thereby reducing the drying cost in the veneers production process, which is normally intensive energy process.

\section{Conclusions}

A novel physical treatment, the perforation of PVC films, was developed and the treated films were used to produce PVCwood composite plywood. An orthogonal design $\mathrm{L}_{16}\left(4^{5}\right)$ was employed to investigate the combined effects of the hot pressing time, hot pressing temperature and the diameter of PVC films perforation on the physical and mechanical properties of plywood composites. The heat transfer mechanism in the composites during hot pressing process was also studied. Some conclusions could be drawn as follows: (1) the composite plywood prepared under the process parameters of hot pressing temperature of $170{ }^{\circ} \mathrm{C}$, hot pressing time of $7 \mathrm{~min}$, veneer initial moisture content of $11 \%$ and PVC films perforation diameter of $15 \mathrm{~mm}$ could reach the optimum mechanical properties. (2) The perforation of PVC films was able to improve the heat transfer significantly. Compared with the composite plywood with unperforated PVC films, the hot pressing time of the plywood laminates prepared under the optimal process conditions was shortened by $51 \mathrm{~s}$, which greatly improved the production efficiency of the enterprise. (3) The interfacial compatibility between the veneer and the PVC films was analyzed by field emission scanning electron microscope (FE-SEM). It was found that the PVC plastic films melted sufficiently during the hot pressing process and penetrated into the interior of the veneer to form a good mechanical adhesive force, which was beneficial to the bonding strength.

\section{Conflicts of interest}

There are no conflicts to declare.

\section{Acknowledgements}

The authors are grateful for the financial supports of Science \& Technology Program in Fujian Province of China (2019H6011) and Science \& Technology Innovation Program in Fujian Agriculture and Forestry University of China (CXZX2017375).

\section{References}

1 M. Z. Fan, Constr. Build. Mater., 2012, 30, 447-454.
2 R. R. Pan, F. L. Fan, Y. Li and X. J. Jin, $R S C A d v .$, 2016, 6, 32960-32966.

3 S. Hirschmüller, J. Pravida, R. Marte and M. Flach, Wood Sci. Technol., 2018, 52, 1061-1092.

4 K. Sumin, K. Hee-Soo, K. Hyun-Joong and H. S. Yang, Constr. Build. Mater., 2008, 22, 2141-2146.

5 L. Chang, Z. Wang, L. Gao and W. J. Guo, Chin. For. Sci. Technol., 2007, 6, 9-13.

6 T. Cui, K. L. Song and S. B. Zhang, For. Sci. Pract., 2010, 12, 218-222.

7 B. B. Adhikari, V. Kislitsin, P. Appadu, M. Chae, P. Choi and D. C. Bressler, RSC Adv., 2018, 8, 2996-3008.

8 J. Luo, C. C. Li, X. N. Li, J. L. Luo, Q. Gao and J. Z. Li, RSC Adv., 2015, 5, 62957-62965.

9 J. Luo, J. L. Luo, Y. Cheng, W. Zhang, J. Z. Li, Q. Gao and H. Chen, RSC Adv., 2015, 5, 100849-100855.

10 M. Dirk, P. Burkhard, A. Jochen, G. Jan, M. Peter and S. Tunga, Wood Sci. Technol., 2016, 50, 313-331.

11 J. Kajaks, K. Kalnins and R. Naburgs, Int. Wood Prod. J., 2017, 9, 1-7.

12 J. Kajak, K. Kalnins and J. Matvejs, Key Eng. Mater., 2018, 762, 226-230.

13 Y. H. Zhou, M. Z. Fan and L. Y. Lin, Polym. Test., 2017, 58, 292-299.

14 L. Chang, Q. H. Tang, L. Gao, L. Fang, Z. Wang and W. J. Gao, Eur. J. Wood Wood Prod., 2016, 76, 1-11.

15 J. P. Rao, Y. H. Zhou and M. Z. Fan, Polymers, 2018, 10, 266. 16 Y. Zhou, M. Z. Fan and L. H. Chen, Composites, Part B, 2016, 101, 31-45.

17 J. A. Kajaks, G. G. Bakradze, A. V. Viksne, S. A. Reihmane, M. M. Kalnins and R. Krutohvostov, Mech. Compos. Mater., 2009, 45, 643-650.

18 J. Follrich, U. Müller and W. Gindl, Holz Roh- Werkst., 2006, 64, 373-376.

19 A. Dieste, A. Krause, S. Bollmus and H. Militz, Holz RohWerkst., 2008, 66, 281-287.

20 L. M. Matuana, J. J. Balatinecz and C. B. Park, Polym. Eng. Sci., 2010, 38, 765-773.

$21 \mathrm{~W}$. Song, W. B. Wei, D. D. Wang and S. B. Zhang, BioResources, 2017, 12, 8320-8339.

22 K. Murata, Y. Watanabe and T. Nakano, Materials, 2013, 6, 410-420.

23 A. Temiz, S. Akbas, I. Aydin and C. Demirkir, Wood Sci. Technol., 2016, 50, 179-191.

$24 \mathrm{~W}$. Song, W. B. Wei, D. D. Wang and S. B. Zhang, BioResources, 2017, 12, 8320-8339.

25 Q. X. Lin, China Wood-Based Panels, 2016, 23, 19-20.

26 M. Seki, T. Miki, S. Tanaka, I. Shigematsu and K. Kanayama, Procedia Eng., 2014, 81, 855-860.

27 B. C. Bal and Ý. Bektap, Maderas: Cienc. Tecnol., 2014, 16, 99108.

28 D. S. Dai and M. Z. Fan, Vib. Spectrosc., 2011, 55, 300-306.

29 C. Sonnenfeld, H. Mendil-Jakani, R. Agogué, P. Nunez and P. Beauchêne, Compos. Struct., 2017, 171, 298-305.

30 B. R. Zhuang, Y. P. Zhan, W. Y. Huang, H. L. Ye and Y. Q. Xie, J. Hazard. Mater., 2018, 357, 271-278. 